\title{
Letters
}

Letters, which may not necessarily be published in full, should be restricted to not more than 250 words. When relevant, comment on the letter is sought from the author. Due to production schedules, it is normally not possible to publish letters received in response to material appearing in a particular issue earlier than the second or third subsequent issue.

\section{Severe hyponatraemia due to mirtazapine}

Editor, - Dr Cheah and Ms Ladhams highlighted an important interaction between medications prescribed for a 79-year-old woman (Aust Prescr 2008;31:97). A diagnosis of inappropriate antidiuretic hormone secretion (SIADH) can only be made when common causes, such as the use of diuretics, are excluded. ${ }^{1}$ Therefore, it is probable that frusemide contributed to the presentation. A serum sodium concentration prior to the initiation of mirtazapine would have been helpful.

The risk factors for developing SIADH (previously presented as relating to mirtazapine only) are applicable to most psychotropic medications, including duloxetine, venlafaxine, fluoxetine, paroxetine, citalopram, escitalopram, tricyclic antidepressants, neuroleptics and carbamazepine..$^{2,3,4}$ Thus, to rechallenge the patient with mirtazapine would be necessary and acceptable, both to disprove the null hypothesis and because the occurrence of the adverse event cannot be predicted when using another drug. ${ }^{2,3}$

The relevant question is how to treat depression in the elderly, who have a greater probability of developing SIADH. A review suggests that hyponatraemia induced by selective serotonin reuptake inhibitors, in particular, may be a transient effect to which the patient develops tolerance. ${ }^{2}$

Alexander D Franke Intern

\section{Slav H Kostov}

Consultant Psychiatrist

Royal Perth Hospital

\section{References}

1. Bartter FC, Schwartz WB. The syndrome of inappropriate secretion of antidiuretic hormone. Am J Med 1967;42:790-806.

2. Kirby $D$, Ames D. Hyponatraemia and selective serotonin re-uptake inhibitors in elderly patients. Int J Geriatr Psychiatry 2001;16:484-93.
3. Madhusoodanan S, Bogunovic OJ, Moise D, Brenner R, Markowitz S, Sotelo J. Hyponatraemia associated with psychotropic medications. A review of the literature and spontaneous reports. Adverse Drug React Toxicol Rev 2002;21:17-29.

4. Ellison DH, BerlT. The syndrome of inappropriate antidiuresis. N Engl J Med 2007;356:2064-72.

\section{Dr Cheah and Ms Ladhams, authors of the Medicinal mishap, comment:}

We agree that the diagnosis of SIADH requires exclusion of other causes, including diuretic therapy. The patient had been treated with frusemide for years prior to presentation with a normal serum sodium. Frusemide was ceased on admission and recommenced at day 10 without a subsequent fall in sodium. We also noted that concomitant use of other drugs which cause hyponatraemia is a risk factor for mirtazapineinduced hyponatraemia. In fact most patients who develop severe hyponatraemia have more than one contributing cause. $^{1}$

While many antidepressant drugs are associated with hyponatraemia, ${ }^{2}$ we argue that rechallenge with mirtazapine in this setting is neither safe nor appropriate given the profound and rapid fall in serum sodium precipitating hospital admission. Our purpose was to highlight mirtazapine-induced hyponatraemia which is only rarely described in the literature and not listed in either the product information or MIMS.

\section{References}

1. Clayton JA, Le Jeune IR, Hall IP. Severe hyponatraemia in medical in-patients: aetiology, assessment and outcome. QJM 2006;99:505-11.

2. Madhusoodanan S, Bogunovic OJ, Moise D, Brenner R, Markowitz S, Sotelo J. Hyponatraemia associated with psychotropic medications. A review of the literature and spontaneous reports. Adverse Drug React Toxicol Rev 2002;21:17-29.

\section{Australian Medicines Handbook 2009}

The 2009 edition of the Australian Medicines Handbook is now available. It includes new monographs on medicines marketed during 2008 and updated content, reflecting changed evidence and practice.

Advice from new practice guidelines has been incorporated in areas such as hypertension and rheumatoid arthritis, and safety information has been updated.

The 984-page paperback edition of the handbook, and other formats, can be ordered online at www.amh.net.au or by phoning (08) 83036977 . 